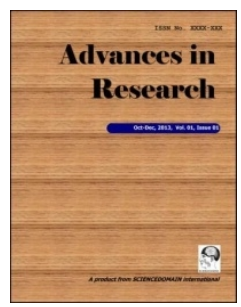

\title{
Corrosion Performance of Steel Coated with Different Duplex Systems and Exposed to Salt Spray and Continuous Immersion Tests
}

\author{
A. R. Di Sarli ${ }^{{ }^{*}}$ and C. I. Elsner ${ }^{1,2}$ \\ ${ }^{1}$ CIDEPINT: Research and Development Centre in Paint Technology (CICPBA-CONICET LA \\ PLATA); Av. 52 s/n entre 121 y 122. CP. B1900AYB, La Plata, Argentina. \\ ${ }^{2}$ Engineering School, National University of La Plata, Av. 1 Esq. 47. CP. B1900TAG, \\ La Plata, Argentina. \\ Authors' contributions \\ This work was carried out in collaboration between both authors. Both authors have actively \\ contributed to carry out each step of the present paper. Both authors read and approved the \\ final manuscript. \\ Original Research Article \\ Received $17^{\text {th }}$ December 2013 \\ Accepted $10^{\text {th }}$ February 2014 \\ Published $22^{\text {nd }}$ February 2014
}

\section{ABSTRACT}

$55 \% \mathrm{Al}-\mathrm{Zn}$ alloy coated steel sheets pre-treated with $5 \% \mathrm{Fe}\left(\mathrm{NO}_{3}\right)_{3}+15 \% \mathrm{H}_{3} \mathrm{PO}_{4}$ solution, coated with acrylic (AC), alkyd (AQ), vinyl (VL), solvent-based epoxy (ES) or waterborne epoxy (EA) corrosion-inhibiting primers + a barrier topcoat alkyd paint, and exposed to different media were studied. Exposure conditions included salt spray or continuous immersion in solutions containing chloride or sulphate ions. The state of the exposed samples was evaluated by visual inspections, standardized physicochemical tests and electrochemical impedance (EIS) measurements. Their results allowed inferring that: 1) under immersion conditions, the best performance was offered by the ES samples; 2) most of the painting systems performed satisfactorily during their exposure to the salt spray chamber; and 3) the correlation between them permitted to explain some problems arising in service and opened the door to extend the useful life by adjusting the painting system formulation. 
Keywords: Steel/55\%Al-Zn; painting systems; salt spray; immersion tests; corrosion; blistering; EIS.

\section{INTRODUCTION}

The steel galvanic protection by means of zinc or zinc alloys is a common example, owing not only to the fact that the zinc, being electrochemically more active than the steel, corrodes preferentially, but also to the barrier effect of the corrosion products precipitated on the metallic surface. However, if the exposure conditions are such that the medium contains strongly aggressive species like chloride or sulphate ions, the zinc could dissolve forming soluble, less dense and scarcely protective corrosion products, which sometimes lead to localized corrosion [1-5]. Aluminum coatings have overcome these two factors. Nevertheless, as they cannot provide cathodic protection to exposed steel in most environments, early rusting occur at coating defects and cut edges; besides, these coatings are also subjected to crevice corrosion in marine environments [4]. Attempts to improve the corrosion resistance of zinc and aluminum coatings through alloying were carried out for years until the alloy composed of $55 \% \mathrm{Al}, 1.6 \% \mathrm{Si}$, the rest zinc, which provides an excellent combination of galvanic protection and low corrosion rate, was developed.

Organic coatings applied on the 55\%-Al alloy layer (duplex system) have acquired great significance to control the steel corrosion, mainly in such an aggressive environments that an alloy layer acting alone could not be sufficient for reaching that purpose [5]. This better corrosion protection is attributed to the double action afforded by the $55 \% \mathrm{Al}-\mathrm{Zn}$ layer (cathodic protection + blockage of its defects by the corrosion products), and also by the pigmented paint system (barrier effect + steel corrosion-inhibition) [6].

The organic film permeability is important in metallic substrate corrosion, since this property is directly connected to the permeation of environmental corrosion-inducing chemicals through the polymeric matrix, the chemical composition of the latter, and the presence of pores, voids or other defects in the coating. It is important to note that particularly water and oxygen can permeate the film, at least to some extent, even if none of the intrinsic structural defects is present.

A number of papers have been devoted to establish the corrosion mechanism of painted galvanized steel subjected to exposure conditions such as immersion or salt fog chambers [7-16].

Despite the extrapolation of accelerated test results to the actual coatings performance in their service life is not lineal, it can supply useful information related to the rate and form of the corrosion-inhibiting system degradation. In most cases, such information can help to improve the paint formulation and/or the painting scheme design.

From this point of view, CIDEPINT has an ongoing research program, which deals with the elucidation of physicochemical phenomena occurring within and under paint coatings, considering defects in films, porous films, metal/coating adhesion, surface treatment and/or pre-treatment, corrosion, blistered coatings and cathodic protection. Consequently, as part of that program aimed at defining lifetime prediction models for, in this case, galvanized steel sheets coated with organic films, an investigation related to the role played by the painting system on the deterioration of such systems has been performed. The goal was to study the protective performance of five painting systems applied on pre-treated steel/55\%Al-Zn sheets and subjected to exposure in salt spray fog chamber (ASTM B-117/07a) for 105 days, 
or by continuous immersion in $0.5 \mathrm{M} \mathrm{NaCl}$ (in order to simulate a marine environment), 0.5 $\mathrm{M} \mathrm{Na}_{2} \mathrm{SO}_{4}$ (urban-industrial ambient) or $0.25 \mathrm{M} \mathrm{NaCl}+0.25 \mathrm{M} \mathrm{Na}_{2} \mathrm{SO}_{4}$ solution. At the end of the exposures, the blistering and white corrosion degrees were classified according to ASTM D-714-87/00 and ASTM D-610/08 standards, respectively.

Electrochemical impedance spectroscopy (EIS) measurements to determine the water permeability coefficient of the paint films as well as changes in the electrical and electrochemical properties of each steel/55\%Al-Zn/paint system, as a function of the exposure time, were also performed. The large amount of data collected using this technique was interpreted on the basis of their correlation with some physicochemical processes that are thought to occur in pre-treated steel/55\%Al-Zn/paint film/exposure medium systems.

\section{MATERIALS AND EXPERIMENTAL DETAILS}

\subsection{Samples}

Carbon steel sheets $(15 \times 8 \times 0.2 \mathrm{~cm})$, whose percentual chemical composition, balanced of iron, was: C (0.16); Mn (0.54); $\mathrm{Si}(0.05)$; S (0.01); P (0.01), hot dip coated with a layer of $55 \%$ Al-Zn alloy (Zn 43.33\%; Al 55\%; Si 1.6\%; Pb 0.03\%; Fe 0.04\%, and $22.5 \mu \mathrm{m}$ thickness) were used as the metallic substrate. They were degreased by immersion in $5 \% \mathrm{Na}_{2} \mathrm{CO}_{3}$ solution, rinsed with distilled water to eliminate any possible surface contamination, and then pretreated with $5 \% \mathrm{Fe}\left(\mathrm{NO}_{3}\right)_{3}+15 \% \mathrm{H}_{3} \mathrm{PO}_{4}$ solution under controlled laboratory conditions.

The primers Table 1 were formulated and prepared in the laboratory. According to the literature $[17,18], 30 \%(\mathrm{v} / \mathrm{v})$ of the primers' total pigment content was composed of phosphate anticorrosive pigment, which contained Bentonite $(14 \%), \mathrm{TiO}_{2}(3.5 \%), \mathrm{BaSO}_{4}(3.7 \%)$, Talc $(3.4 \%)$ and Mica (7.0\%). This last pigment was incorporated to improve the paint barrier effect as well as to reduce the flush rusting degree caused by the waterborne paints [19]. In the water- or solvent-base paints, the PVC was $20 \%$ or $40 \%$, respectively. The topcoat paint was an alkyd of commercial-grade type.

Because of the laboratory scale of primer paint elaboration, brushing was the preferred application method while a focused effort to maintain the same conditions for all the samples was made. After the application of the painting systems, the painted plates were placed in a dessicator cabinet until completely dried. Next, measurements of dry film thickness Table 2 were taken with an Elcometer 300 coating thickness gauge, using a bare sanded plate and standards of known thickness as references.

\subsection{Standardized Tests}

To check reproducibility, five specimens of each painting system with their edges masked with a thick wax based coating were tested in a salt spray cabinet for 105 days according to the ASTM B-117/07a standard. During the test, the specimens' position within the cabinet was changed after each periodical visual inspection and EIS measurement, to eliminate the possibility that the position might affect the results. At the end of this test, the size and frequency of blisters, as well as the white corrosion degree, were evaluated according to ASTM D-714-87/00 and ASTM D-610/08 standards, respectively. 
Table 1. Main characteristics of the formulated primers

\begin{tabular}{|c|c|c|c|c|c|c|}
\hline \multirow[t]{2}{*}{ Primer } & \multirow[t]{2}{*}{ Resin } & \multirow[t]{2}{*}{ Solvent } & \multirow[t]{2}{*}{ Plasticizer } & \multicolumn{3}{|c|}{ Pigments } \\
\hline & & & & Anticorrosive & Filler & Hiding \\
\hline Acrylic & $\begin{array}{l}\text { Acrylic- } \\
\text { Styrene }\end{array}$ & Water & ---- & $\begin{array}{l}\text { Zinc Molibdo } \\
\text { phosphate }\end{array}$ & Bentonite & $\begin{array}{l}\mathrm{TiO} 2 \\
\text { (rutile) }\end{array}$ \\
\hline Alkyd & Alkyd & $\begin{array}{l}\text { White spirit/ } \\
\text { Toluene } \\
\text { 1:1 (v/v) }\end{array}$ & ---- & $\begin{array}{l}\text { Zinc Molibdo } \\
\text { phosphate }\end{array}$ & $\begin{array}{l}\text { Talk } \\
\text { Mica } \\
\text { Baryte }\end{array}$ & $\begin{array}{l}\mathrm{TiO} 2 \\
\text { (rutile) }\end{array}$ \\
\hline Epoxysolv & $\begin{array}{l}\text { Epoxy- } \\
\text { Polyamide }\end{array}$ & $\begin{array}{l}\text { Xylene/MIK/But } \\
\text { oxyethanol } \\
\text { 13:45:42 (v/v) }\end{array}$ & ---- & $\begin{array}{l}\text { Zinc Molibdo } \\
\text { phosphate }\end{array}$ & $\begin{array}{l}\text { Talk } \\
\text { Mica } \\
\text { Baryte }\end{array}$ & $\begin{array}{l}\mathrm{TiO} 2 \\
\text { (rutile) }\end{array}$ \\
\hline Epoxyaq & * & $\begin{array}{l}\text { Water + } \\
\text { Coalescent }\end{array}$ & ---- & $\begin{array}{l}\text { Zinc Molibdo } \\
\text { phosphate }\end{array}$ & $\begin{array}{l}\text { Talk } \\
\text { Mica } \\
\text { Baryte }\end{array}$ & $\begin{array}{l}\mathrm{TiO} 2 \\
\text { (rutile) }\end{array}$ \\
\hline Vinyl & $* *$ & $\begin{array}{l}\text { MIK/Toluene } \\
1: 1(\mathrm{v} / \mathrm{v})\end{array}$ & $\begin{array}{l}\text { Tricresyl } \\
\text { Phosphate }\end{array}$ & $\begin{array}{l}\text { Zinc Molibdo } \\
\text { phosphate }\end{array}$ & $\begin{array}{l}\text { Talk } \\
\text { Mica } \\
\text { Baryte }\end{array}$ & $\begin{array}{l}\mathrm{TiO} 2 \\
\text { (rutile) }\end{array}$ \\
\hline
\end{tabular}

\subsection{Electrochemical Measurements}

To carry out the impedance measurements, a cylindrical clamp-on acrylic (polymethyl methacrylate) cell was positioned on the painted panel by an O-ring defining a surface area of $15.9 \mathrm{~cm}^{2}$. An aperture at the top of this three-electrode electrochemical cell contained a Pt$\mathrm{Rh}$ mesh counter-electrode with negligible impedance, oriented parallel to the working electrode (painted metal surface). A glass-linear Saturated Calomel tipped Reference Electrode (SCE), referred to in the text, was positioned, together with the counter-electrode, close to the exposed painted steel surface panel. For the immersion tests, the electrolytes were $0.5 \mathrm{M} \mathrm{NaCl}, 0.5 \mathrm{M} \mathrm{Na}_{2} \mathrm{SO}_{4}$ or $0.25 \mathrm{M} \mathrm{NaCl}+0.25 \mathrm{M} \mathrm{Na}_{2} \mathrm{SO}_{4}$ solutions, at a pH of 6.5 . After exposing samples to the salt fog chamber, they were subjected to the periodical electrochemical measurements performed after 1 hour of wetting with the electrolyte formed by dissolving the salts deposited on the sample surface in $100 \mathrm{ml}$ of distilled water. Impedance spectra were obtained with a Solartron $1255 \mathrm{FRA}^{\circledR}$ coupled to an Impedance Potentiostat-Galvanostat Omnimetra PG-19A ${ }^{\circledR}$, and both controlled by the Zplot ${ }^{\circledR}$ software. Impedance spectra collected between $10^{5} \mathrm{~Hz}$ and $10 \mathrm{mHz}$ were analyzed and interpreted on the basis of equivalent electrical circuits, optimizing the values of the circuit parameters by using Boukamp' program [20].

The value of the water permeability coefficient for each painted steel/55\% I- $\mathrm{Zn} /$ solution system was also determined. The dielectric capacitance evolution was measured as a function of the immersion time until a constant value was attained. Such measurements were performed with the same equipment arrangement described above, in the potentiostatic mode and at a frequency of $2.10^{4} \mathrm{~Hz}$. The water permeability, diffusion and solubility coefficients were obtained with the calculus method reported elsewhere [21]. All the electrochemical experiments were carried out at laboratory temperature $\left(23 \pm 2^{\circ} \mathrm{C}\right)$ and with the electrochemical cell in a Faraday cage to reduce external interferences as much as possible. 
Taking into account that the corrosion behavior of passivated, painted and/or multi coated materials strictly depends on the production procedure, all the tests were carried out on three replicates of each sample type and the average results obtained for them are reported in the following tables and figures.

\section{RESULTS AND DISCUSSION}

\subsection{Blistering/White Corrosion Degrees}

The blistering/corrosion data obtained for replicates of the samples described in Table 2, and placed in the salt spray cabinet for 105 days, are summarized in Table 3 . It can be seen that at the end of the test, only $A C$ samples showed the onset of blisters development, while the main body of the $A Q, E S, E A$ and $V L$ samples remained without any visible change. In general, all of the white rusting data reveal that under the current experimental conditions the anticorrosive + barrier protection provided by the overall coating systems was highly satisfactory.

Table 2. Identification and total thickness of the painting systems

\begin{tabular}{llll}
\hline Painting System & $\begin{array}{l}\text { Anticorrosive } \\
\text { Primer }\end{array}$ & $\begin{array}{l}\text { Topcoat } \\
\text { Paint }\end{array}$ & $\begin{array}{l}\text { Total Thickness } \\
(\mu \mathrm{m})\end{array}$ \\
\hline AC & Acrylic & Alkyd & $125 \pm 10$ \\
AQ & Alkyd & Alkyd & $120 \pm 10$ \\
ES & Epoxy $_{\text {solv }}$ & Alkyd & $119 \pm 10$ \\
EA & Epoxy $_{\text {aq }}$ & Alkyd & $130 \pm 10$ \\
VL & Vinyl & Alkyd & $115 \pm 10$ \\
\hline
\end{tabular}

Table 3. Blistering (ASTM D-714) and White Rusting (ASTM D-610) Degrees shown by the samples after the salt spray test

\begin{tabular}{lll}
\hline System & Blistering & White Rusting \\
\cline { 2 - 3 } & Blister Size/ Frequency & $\begin{array}{l}\text { White Rusting Grade/ Percent of } \\
\text { Rusted Surface }\end{array}$ \\
\hline AC & $4 / F$ & 10 \\
AQ & 10 & 10 \\
ES & 10 & 10 \\
EA & 10 & 10 \\
VL & 10 & 10 \\
\hline \multicolumn{2}{r}{ ASTM D-714 specifications guide-size: 10, comment: no blister; frequency: few (F), size: 4, } \\
\multicolumn{3}{r}{ comment: progressively larger size. } \\
& ASTM D-610 specifications guide-for rust grade 10, the percentage area rusted was 0.
\end{tabular}

Table 4 summarizes blistering/white corrosion data for intact replicates of the steel/55\%Al$\mathrm{Zn} /$ paints systems subjected to continuous immersion in $0.5 \mathrm{M} \mathrm{NaCl}, 0.5 \mathrm{M} \mathrm{Na}_{2} \mathrm{SO}_{4}$ or 0.25 $\mathrm{M} \mathrm{NaCl}+0.25 \mathrm{M} \mathrm{Na}_{2} \mathrm{SO}_{4}$ solution for 120 days. As can be seen, not all the samples showed blistering after being submerged in $0.5 \mathrm{M} \mathrm{NaCl}$ or $0.5 \mathrm{M} \mathrm{Na}_{2} \mathrm{SO}_{4}$ solutions, but all of them showed some degree of blistering in $0.25 \mathrm{M} \mathrm{NaCl}+0.25 \mathrm{M} \mathrm{Na}_{2} \mathrm{SO}_{4}$. According to Ritter et al. [22], it may be supposed that during the first stage of immersion in aqueous saline solutions, different amounts of water, oxygen, and ionic species can permeate the paint coating. Because of this mass transport, the blistering caused by the water permeation proceeds as 
follows. The mechanism of formation and growth of the blisters under the paint film tending to certain frequencies and sizes may be explained by assuming that water permeation through an organic coating develops blisters at small-localized regions where local failure of the paint film adhesion takes place. As exposure to the aqueous electrolyte continues, these areas grow and coalesce causing a portion, or the total exposed area, to become delaminated. The periodic visual inspection and standardized characterization of the painted surface allowed monitoring the starting and evolution of the blistering/corrosion processes leading to reduced aesthetic and mechanical properties of each sample.

With regard to the white corrosion appearance, the visual inspections determined that a reasonably effective corrosion inhibitive action was offered by most of the painting systems. After 120 days of immersion in any of the aggressive solutions the percent of corroded areas was $0.3 \%$ in $\mathrm{AC}$ samples, $0.1 \%$ (in $\mathrm{NaCl}$ ) and $0.03 \%$ (in $0.25 \mathrm{M} \mathrm{NaCl}+0.25 \mathrm{M} \mathrm{Na}_{2} \mathrm{SO}_{4}$ ) in $\mathrm{AQ}$ samples, and $0.3 \%$ (in $\mathrm{NaCl}$ ) in $\mathrm{EA}$ samples, the rest of the values was 10 (no corrosion).

\subsection{Corrosion Potential}

Rest or corrosion potential $\left(\mathrm{E}_{\text {corr }}\right)$ measurements as a function of the exposure time to aqueous media have been successfully used as a simple tool to study the corrosion protection afforded by organic coatings [23-27]. Fig. 1a shows that for the 105 days of exposure in the salt spray cabinet the $E_{\text {corr }}$ displacements were not uniform. With different slopes, they moved from their initial value towards ones that were more negative but without reaching the corresponding to the bare $55 \% \mathrm{Al}-\mathrm{Zn}$ alloy $(\approx-1.1 \mathrm{~V} / \mathrm{SCE})$. Then, the potential evolution was characterized by a large scattering due to its dependence on the specific protective properties afforded by the applied painting system and, consequently, on the particular electrochemical conditions developed at the complex steel/55\%Al-Zn/painting system/electrolyte interfaces. Approximately 100 days after exposure the values measured for $A Q$ and EA samples tended towards values closer to those of the bare steel/55\%Al-Zn, indicating that $55 \% \mathrm{Al}-\mathrm{Zn}$ alloy corrosion could initiates in a short time.

The $E_{\text {corr }}$ values measured for all the tested specimens submerged in $0.5 \mathrm{M} \mathrm{Na}_{2} \mathrm{SO}_{4}, 0.5 \mathrm{M}$ $\mathrm{NaCl}$ or $0.25 \mathrm{M} \mathrm{NaCl}+0.25 \mathrm{M} \mathrm{Na}_{2} \mathrm{SO}_{4}$ solutions are displayed in Fig. 1b-d. As can be seen, the potential evolution was characterized by a large scattering due to the above-mentioned reasons.

Fig. 1c shows that the higher permeability to water Table 5, which makes easier the access of chloride ions to the metal/paint interface, enabled an accelerated failure of the $E A, A Q, V L$ and $A C$ samples' protection mechanism. This caused the $E_{\text {corr }}$ displacement to move closer to the values of the bare steel/55\%Al-Zn potential in the same medium. In essence, the more negative the potential became, the more susceptible to corrosion the underlying steel/55\%Al$\mathrm{Zn}$ surface became. The visual inspection helped to confirm that there was paint blistering in the $A C, A Q$ and $V L$ samples as well as the characteristic white corrosion products of the $55 \% \mathrm{Al}-\mathrm{Zn}$ alloy at localized places of the AC, AQ and EA samples (see Table 4). In the latter case, no blistering was detected. This was attributed to stronger adhesion forces at the steel/55\%Al-Zn/epoxy-base primer (EA) interface than at the acrylic and alkyd one (AQ and $A C$ samples). The same figure illustrates that the initial Ecorr of VL samples changed towards values more negative, but after a certain period they fluctuated several hundreds of milivolts probably due to both the blocking of pores by the $55 \% \mathrm{Al}-\mathrm{Zn}$ corrosion products and the appearance of new failures in weaker areas of the paint layer. Finally, the best and stable protective behavior marked by the Ecorr values of the ES samples was attributed to factors such as the high barrier resistance supplied by the painting system, the inhibitive action of 
the anticorrosive pigment as well as the good interfacial adhesion acting together. As a result, they were effective enough as to avoid electrochemical activity at the paint/metal interface and, therefore, changes in the cathodic/anodic areas relationship [28].
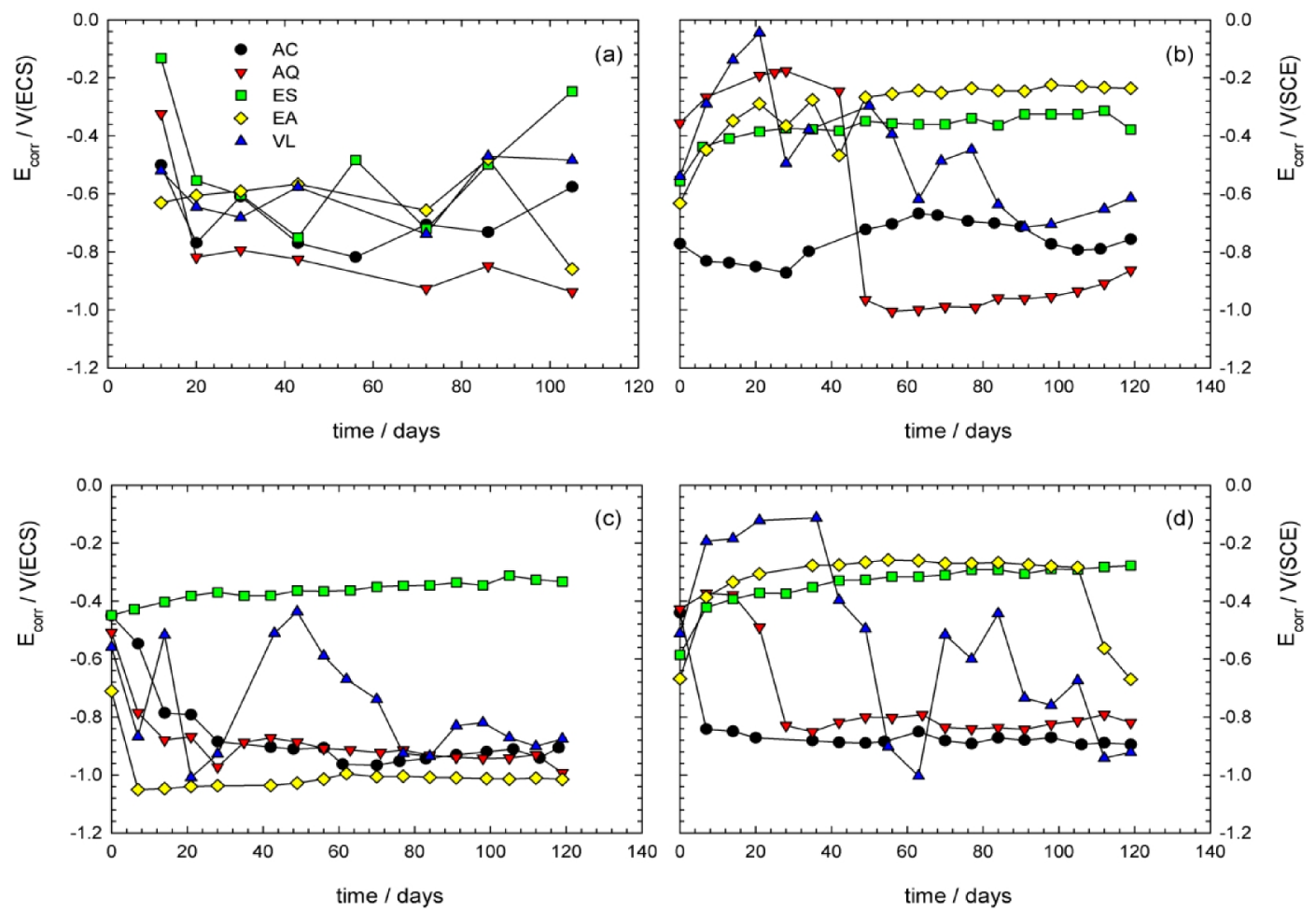

Fig. 1. Plots showing the time dependence of the corrosion potential $\left(E_{\text {corr }}\right)$ during the exposure of the AC, AQ, ES, EA and VL samples to a) salt spray cabinet for 105 days;

b) $0.5 \mathrm{M} \mathrm{Na}_{2} \mathrm{SO}_{4}$; c) $0.5 \mathrm{M} \mathrm{NaCl}$; and d) $0.25 \mathrm{M} \mathrm{NaCl}+0.25 \mathrm{M} \mathrm{Na}_{2} \mathrm{SO}_{4}$ solutions for 120 days

The time dependence of the $E_{\text {corr }}$ corresponding to all the samples submerged in $0.5 \mathrm{M}$ $\mathrm{Na}_{2} \mathrm{SO}_{4}$ Fig. $1 \mathrm{~b}$ or $0.25 \mathrm{M} \mathrm{Na}_{2} \mathrm{SO}_{4}+0.25 \mathrm{M} \mathrm{NaCl}$ solutions Fig. $2 \mathrm{~d}$ shows similar evolution in the replicated samples. While the measured potentials of $A C$ and $A Q$ samples displaced more or less rapidly towards values more negative, those corresponding to the VL ones remained fluctuating from the beginning up to the end of the test. On the other hand, the anticorrosive protection provided by the EA, and particularly by the ES painting system, was highly effective and stable along the entire test time as their $E_{\text {corr }}$ remained in the range -0.5 to $-0.2 \mathrm{~V} / \mathrm{SCE}$. 
Table 4. Blistering and White Rusting Degrees shown by the samples after 120 days immersion in

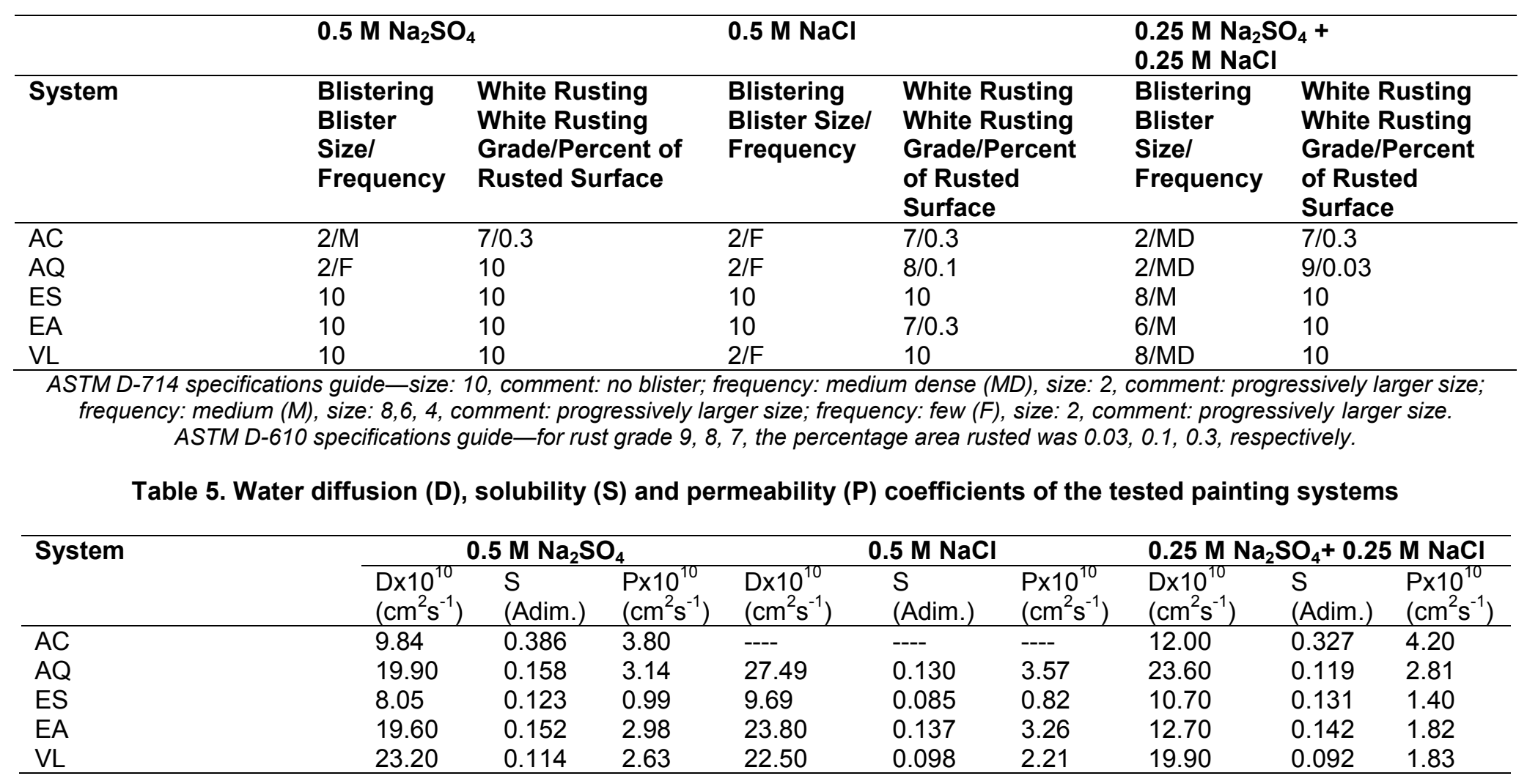


Since the main difference among the steel/55\%Al-Zn/painting systems was the primer formulation used in each case, it is assumed that the magnitude of the $E_{\text {corr }}$ displacements may be particularly associated with both the relative ease with which the water and ionic species permeate the paint film and the primer's protective properties. However, independent of the applied painting system, and from the thermodynamic point of view, the metallic substrate was relatively protected from corrosive attack throughout the tests. This conclusion arises from the fact that the corrosion potential values measured in each painted steel $/ 55 \% \mathrm{Al}-\mathrm{Zn}$ panel were mostly nobler than those corresponding to the bare steel/55\%Al $\mathrm{Zn}$ sheets subjected to the same experimental conditions. This protection may be attributed to the sum of effects acting simultaneously such as the paint system barrier protection and the pore blockage with the corrosion products mostly produced from the zinc dissolution reactions due to self-corrosion and/or when it galvanically protects the underlying steel. When this kind of protection is lost, or at least significantly diminished, other protective forms, for example those exerted by the anticorrosive zinc molybdophosphate pigment, certainly continue being active. Some authors suggested that both the phosphate and molybdenum compounds contribute to the anticorrosive protective mechanism through an effective steel repassivation at the underpaint crevices and pits $[29,30]$.

\subsection{Eis}

As far as the paint film is concerned, its barrier and permeability properties are of great interest because they control the transport of corrosive chemicals as well as the dissolution of the active pigments and their supply to the metal substrate. Reliable data on water permeability, corrosion potential and impedance evolution of coated metals provides valuable information to select and design the most adequate protective paint system for each practical situation.

\subsubsection{Water permeability}

According to Ritter [22], it may be assumed that different amounts of water, oxygen and ions can permeate the organic coating in the first hours of immersion in saline solution. In the painted pre-treated steel $/ 55 \% \mathrm{Al}-\mathrm{Zn}$ panels tested, a first step of such a process could be attributed to the fact that the topcoat alkyd paint contains an appreciable amount of watersoluble material and tends to absorb water and swell [31]. In addition, the absorbed water has some plasticizing effect on the alkyd film structure and, consequently, it facilitates the movement of molecules through the paint system.

The water permeability (P), diffusion (D) and solubility (S) coefficients obtained for the tested specimens with the calculus method reported elsewhere [21] are shown in Table 5 as an example, it can be seen that, under immersion conditions, the best performance was offered by the ES system since it averaged the lowest water permeability values $\left(0.99 \times 10^{-10}\right.$ $\left.\mathrm{cm}^{2} \mathrm{~s}^{-1}\right),\left(0.82 \times 10^{-10} \mathrm{~cm}^{2} \mathrm{~s}^{-1}\right)$ and $\left(1.40 \times 10^{-10} \mathrm{~cm}^{2} \mathrm{~s}^{-1}\right)$ when immersed respectively in $\mathrm{Na}_{2} \mathrm{SO}_{4}, \mathrm{NaCl}$ or $\mathrm{Na}_{2} \mathrm{SO}_{4}+\mathrm{NaCl}$ solutions. This better protective behavior was attributed to the excellent barrier effect afforded by the epoxy-base solvent paint, plus that exerted by the topcoat paint. On the contrary, the worst performance corresponded to the AC samples in $\mathrm{NaCl}$ solution since its water permeability could not be measured. This situation arises when the water permeability of the paint film is so high that its dielectric behavior does not comply with the assumptions made to solve the calculation model [21]. Taking into account that the samples tested in the three electrolytes were identical replicates, and that the main experimental difference was the anion $\left(\mathrm{Cl}^{-}, \mathrm{SO}_{4}{ }^{2-}\right.$ or a mixture of both) present in each electrolyte, differences in the obtained results were attributed to several factors. In addition 
to the specific protective properties provided by each paint system, the relatively significant changes showed by the water permeability coefficient would be associated to physicochemical interactions anion-resin functional groups due to the anion size, charge and/or concentration. As was mentioned, some of these factors acting alone or complementarily could change the mechanism and/or energy of interaction between the reactive polar species (polymeric components, pigment particles, etc.) within the paint film and the water molecules, which diffuse through it [32]. Table 5 shows that this assumption is supported by the fact that the value of the permeability, diffusion and solubility coefficients, which are associated to the mobility of the water molecules (diffusion) and the amount of water dissolved within the coating free-volume (solubility), changed with the electrolyte composition. Unfortunately, such results contribute to make less predictable the effectiveness of the barrier properties provided by paint coatings subjected to exposures in ambient contaminated with different chemicals and, consequently, of the anticorrosive protection afforded to the underlying steel/55\%Al-Zn.

\subsubsection{Bode plots}

Fig. 2 illustrates the impedance modulus $(|Z|)$ and the angle phase (Theta) of replicated samples as a function of their exposure time to the salt spray chamber. A fast and simple qualitative analysis of this figure allows inferring that the salt spray test provoked perceptible changes in the modulus and phase angle of the $A C, A Q, E A$ and $E S$ samples impedance spectra, but slight changes in those corresponding to VL samples. However, under this exposure condition it is possible to presume the presence of at least two time constants, one at low frequencies and another at high frequencies.

Figs. 3-5 display the time dependence of the electrochemical impedance corresponding to the $A C, A Q$, EA, ES and VL samples subjected to continuous immersion in $0.5 \mathrm{M} \mathrm{Na}_{2} \mathrm{SO}_{4}$, $0.5 \mathrm{M} \mathrm{NaCl}$ or $0.25 \mathrm{M} \mathrm{NaCl}+0.25 \mathrm{M} \mathrm{Na}_{2} \mathrm{SO}_{4}$ solution for 120 days.

As seen in these figures, changes during the immersion test took place mainly in the $A C$ and $A Q$ samples, and were reasonably in concordance with the blistering and white corrosion degrees shown in Table 4 and the water permeability values in Table 5 . The fluctuating impedance values can be attributed to the dynamic behavior of the steel/55\%Al-Zn/paint interface through which the corrosion products gathered at the bottom of and/or within the coating defects enhancing the coating barrier protection and, therefore, contributing to an increase in the impedance of the protective system at medium and low frequencies. However, as time elapsed, new defects appeared at the weaker (less protective) paint layer areas allowing the induction of corrosion species permeation, and, consequently, the development of new electrochemically active zones.

The fact that the initial substrate attack is localized could be ascribed to the presence of very small defects in the paint layer, which act as an electrical shunt. As the exposure time advances, the equilibrium between the development rate of the corrosion products and their diffusion rate towards the electrolyte may be reached and, consequently, the total impedance fluctuations become small 

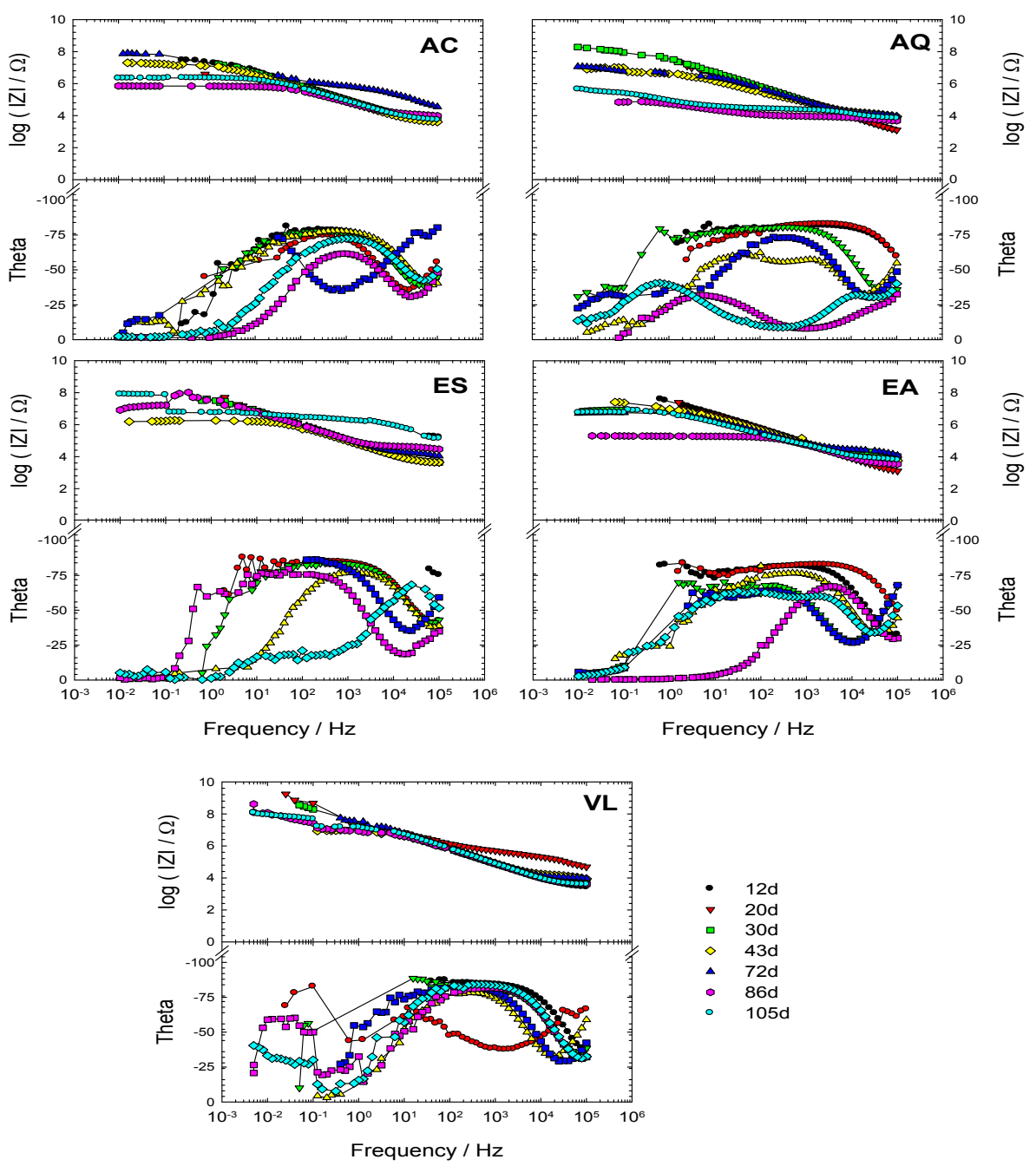

Fig. 2. Bode plots showing the time dependence of the $A C, A Q, E S, E A$ and VL samples impedance during their exposure to salt spray test for 105 days

\subsubsection{Equivalent circuit models}

The painting system and steel/55\%Al-Zn substrate deterioration take place due to processes having complex nature. Consequently, to interpret and explain the time dependence of the acquired impedance data in electrochemical terms, it has been necessary to propose appropriate equivalent circuit models. 

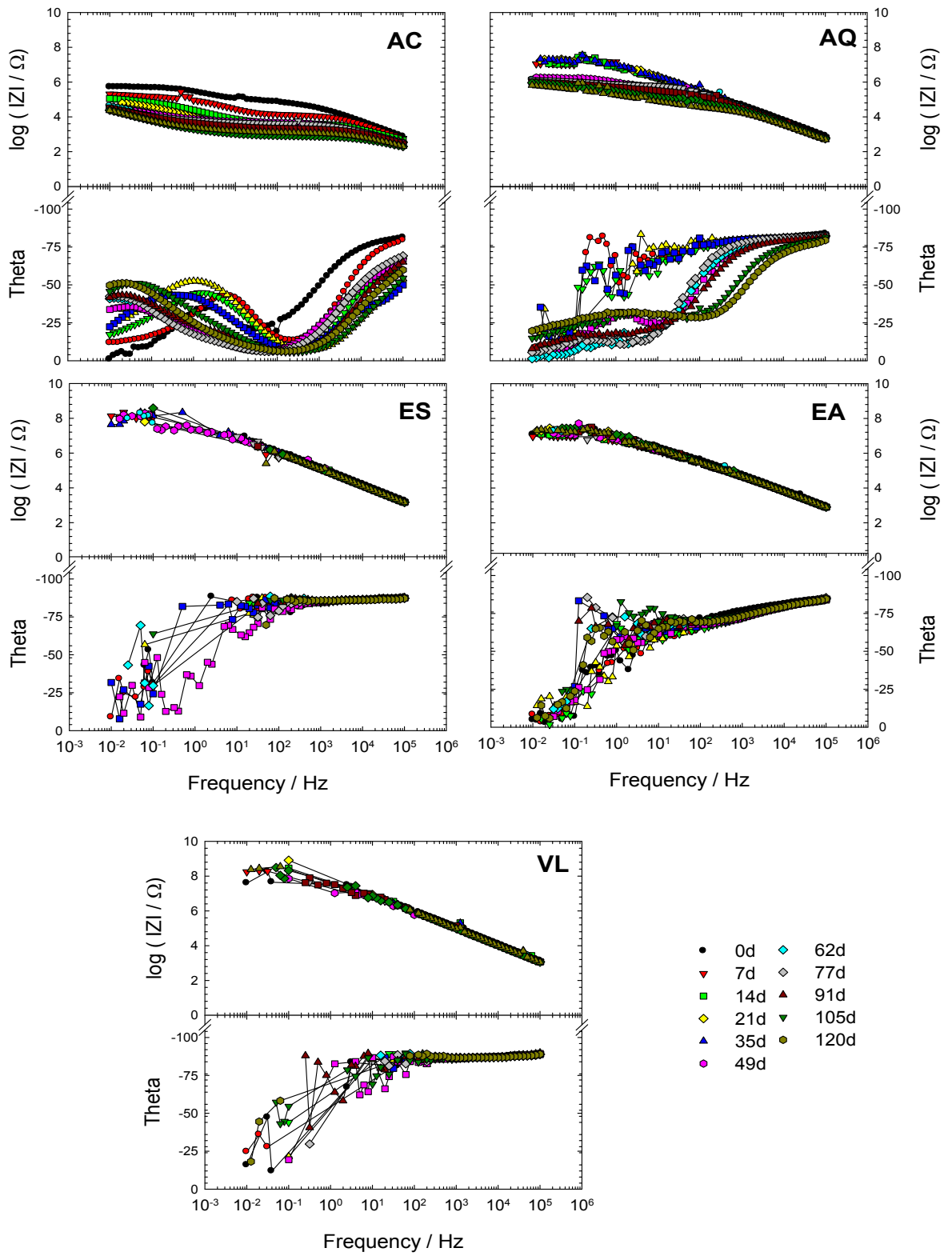

Fig. 3. Bode plots showing the time dependence of the AC, AQ, ES, EA and VL samples impedance during their immersion in $0.5 \mathrm{M} \mathrm{Na}_{2} \mathrm{SO}_{4}$ solution for 120 days 

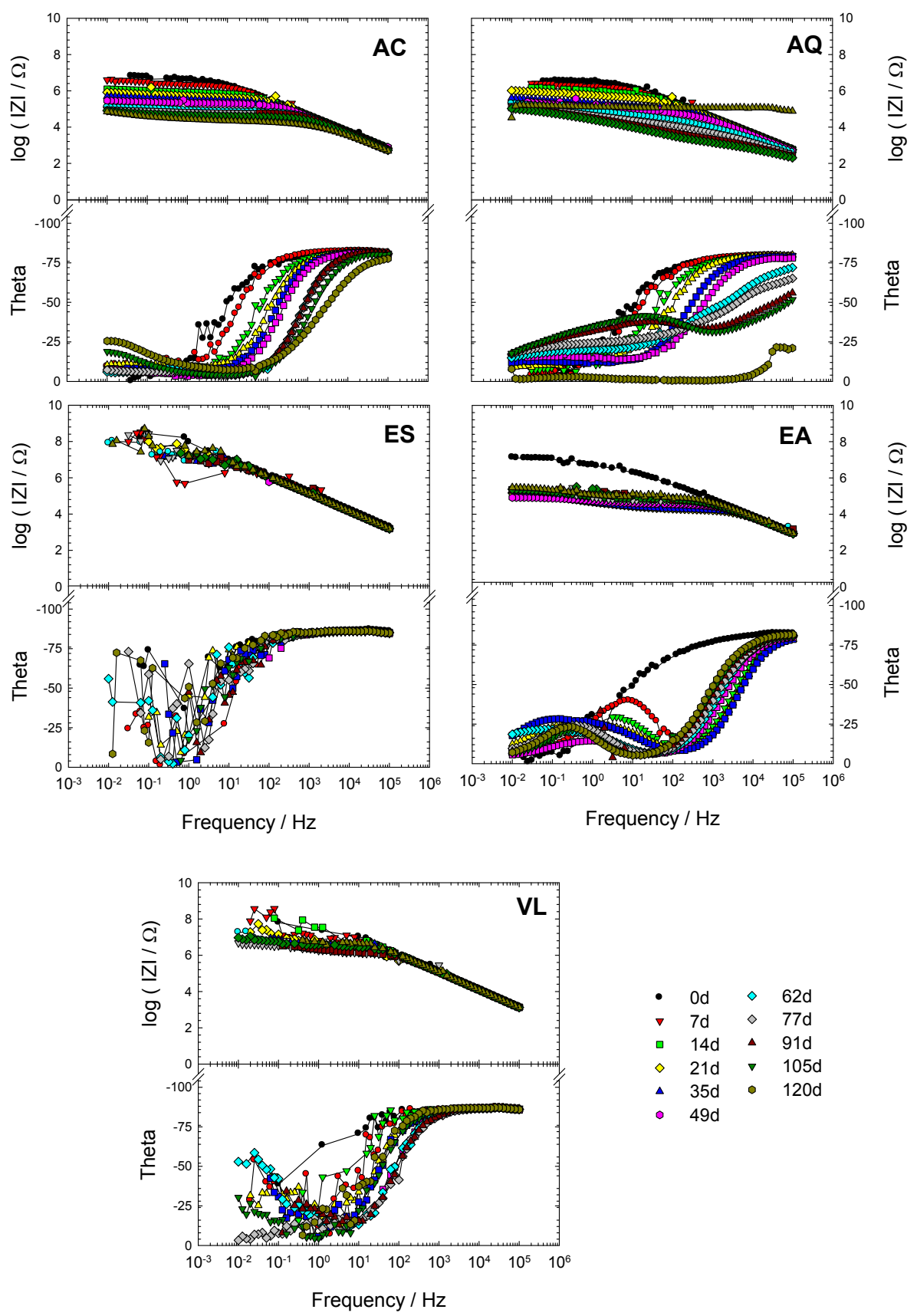

Fig. 4. Bode plots showing the time dependence of the AC, AQ, ES, EA and $\mathrm{VL}$ samples impedance during their immersion in $0.5 \mathrm{M} \mathrm{NaCl}$ solution for 120 days 

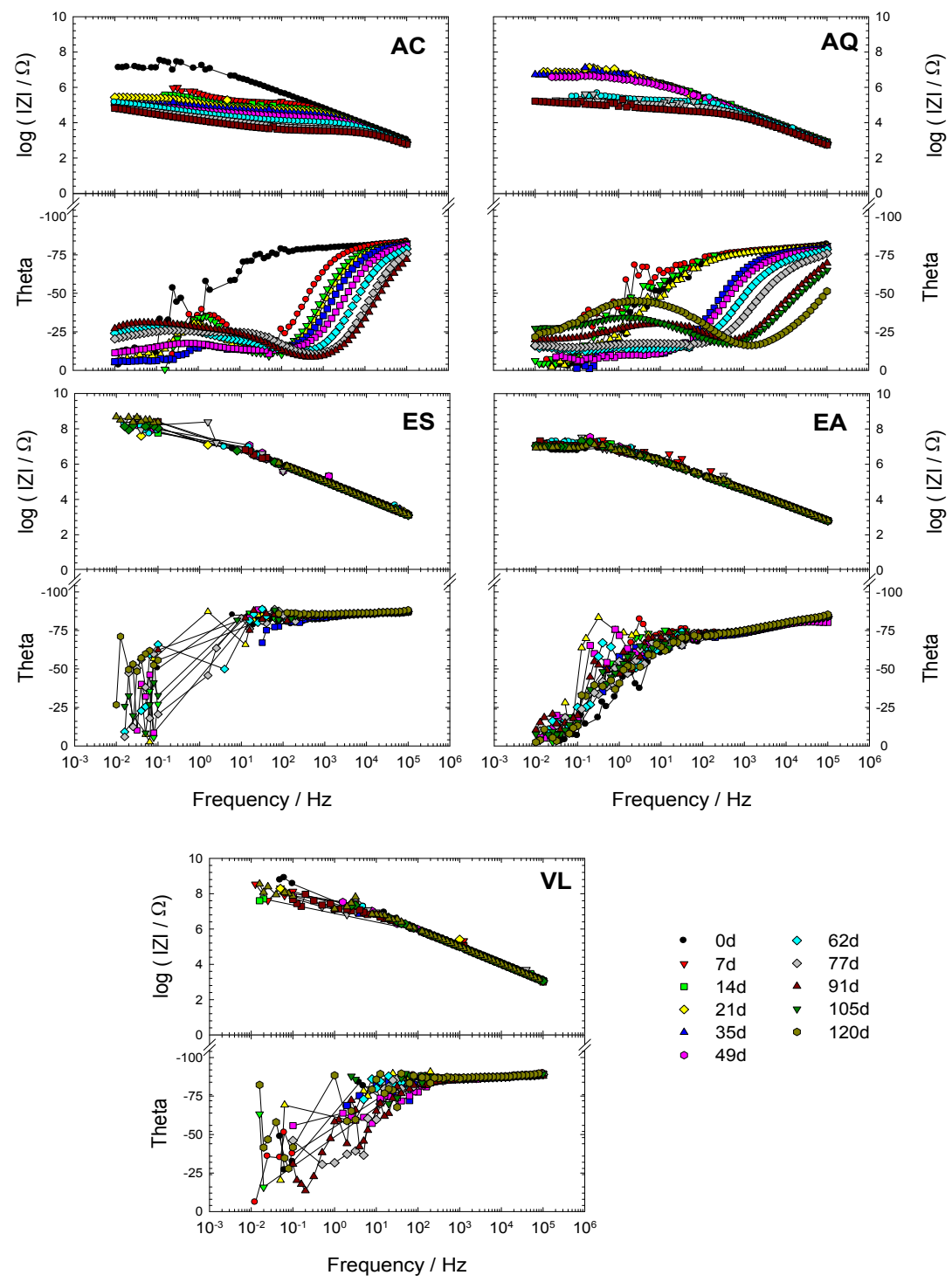

Fig. 5. Bode plots showing the time dependence of the AC, AQ, ES, EA and $V L$ samples impedance during their immersion in $0.25 \mathrm{M} \mathrm{Na}_{2} \mathrm{SO}_{4}+0.25 \mathrm{M} \mathrm{NaCl}$ solution for 120 days

The dynamic character of the painting system barrier properties, the anticorrosive action of specific pigments, the formation of corrosion products and/or changes in the disbonded area are accounted for in the time dependence of the coated steel/electrolyte impedance spectra. Why and how such changes take place is usually explained by associating them to the resistive and capacitive parameters derived from fitting impedance data with non-linear least squares algorithms involving the transfer function of equivalent circuit models [33-38]. In the 
present work, Fig. 6 represents the parallel and/or series connection of some resistors and capacitors, simulating a heterogeneous arrangement of electrolitically conducting paths. In it, $R$ represents the electrolyte resistance between the reference and working (coated steel) electrodes, $R_{1}$ (resistance to the ionic flux) describes paths (pores, low crosslinking) of lower resistance to the electrolyte diffusion short-circuiting the paint film, and $\mathrm{C}_{1}$ is the dielectric capacitance representing the intact part of the same paint film [39]. Once the permeating and corrosion inducing chemicals (water, oxygen and ionic species) reach electrochemically active areas of the substrate, particularly at the bottom of the paint film defects, the metallic corrosion becomes measurable so that its associated parameters, the electrochemical double layer capacitance, $C_{2}$, and the charge transfer resistance, $R_{2}$, can be estimated. Besides, if the corrosion products accumulate within and/or at the bottom of the coating pores, they give rise to the appearance of another time constant $\left(R_{3} C_{3}\right)$, which can be graphically and/or numerically separated [40]. Distortions observed in these resistivecapacitive contributions indicate a deviation from the theoretical models in terms of a time constant distribution due to several possible reasons [41,42]. Since such factors cause the impedance/frequency relationship to be non-linear, they are taken into consideration by replacing one or more capacitive components $\left(\mathrm{C}_{i}\right)$ of the equivalent circuit transfer function by the corresponding constant phase element $Q_{i}(C P E)$, whose impedance dispersion relation is given by: $Z=(j \omega)^{-n} / Y_{0}$, and $n=$ CPE power $=\alpha /(\pi / 2)[20,43]$.

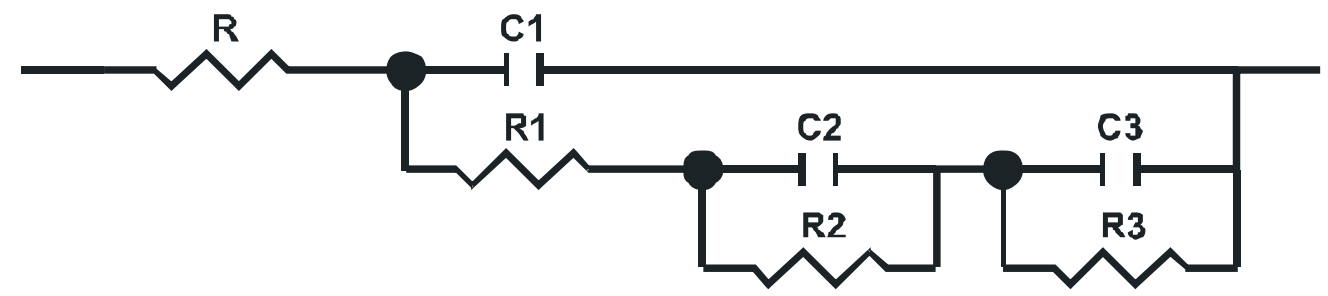

Fig. 6. Equivalent circuit model used for fitting tested samples

Difficulties in providing an accurate physical description of the occurred processes are sometimes found. In such cases, a standard deviation value $\left(\chi^{2}<5 \times 10^{-4}\right)$ between experimental and fitted impedance data may be used as final criterion to define the "most probable circuit" [20]. Examples of the results obtained by using this criterium are shown in Fig. 7.

According to the impedance spectra dispersion, the fitting processes were performed using either the dielectric capacitance $C_{i}$ or the phase constant element $Q_{i}$, however, the $C_{i}$ parameter was used in the following plots to facilitate the results visualization and interpretation.

\subsubsection{Time dependence of the impedance resistive and capacitive components}

\subsubsection{Exposure test to the salt spray chamber}

Fig. 8a shows a representative plot of the coating resistance to the ionic flux $\left(R_{1}\right)$ corresponding to the five painting systems subjected to salt spray chamber exposure for 105 days. It can be seen that after 10 days of testing, $R_{1}$ values between $10^{4}-10^{6} \Omega \mathrm{cm}^{2}$ were obtained for all the painting systems. Elapsed 20 days, such values increased significantly ( $A Q$ samples) or remained stable ( $A C, E S, E A$ and $V L$ samples). As the exposure time 
elapsed, in addition to the $A Q$ samples, the $A C$ and $E S$ samples showed an oscillating behavior of the paint films resistance to the ionic flux. As is illustrated in this figure, the barrier effect afforded by the different painting systems varied between $R_{1} \approx 10^{4}-10^{7} \Omega \mathrm{cm}^{2}$ indicating that the formation and/or changes in the size of the electrolyte pathways continued during the whole test.

Regarding the values of the dielectric capacitance $\left(\mathrm{C}_{1}\right)$ associated to the amount of water dissolved within the intact paint film structure, Fig. 8b shows that, except for those corresponding to the $A Q$ samples, the rest were stable, almost equal and close to $10^{-11}$ $\mathrm{Fcm}^{2}$. Generally, this capacitance value is characteristic of intact paint films. Further, this means that the amount of water uptake could be less than $5 \%$ of the painting system volume [44] over the test.

Impedance spectra deconvolution allowed evaluating the parameters related to both the dissolution of the alloy layer $\left(R_{2}, C_{2}\right)$, and the developed corrosion products $\left(R_{3}, C_{3}\right)$, whose contribution to the overall impedance of the painted steel/ $55 \% \mathrm{Al}-\mathrm{Zn}$ changed dynamically as a function of the exposure time. Figs. 8(c-f) illustrate that the appearance of the time constant associated to the steel/55\%Al-Zn corrosion occurring at the bottom of the paint film defects took place from the first EIS measurement at 12 days of immersion. The evolution of the corrosion process developed in each system is explained in terms of changes in the size of the electrochemically active areas formed on the underlying metallic substrate. Thus, the steep decline showed by the $R_{2}$ values for the $A Q$ and ES systems at 20 days of exposure was associated to an increase of the $55 \% \mathrm{Al}-\mathrm{Zn}$ dissolution areas, which although not detectable by naked eye, caused an increasing corrosion rate because this kinetic variable depends inversely on the $R_{2}$ values. The subsequent increase of $R_{2}$ was ascribed to the formation of a dense and compact layer of primarily hydrated zinc corrosion products, which grew and remained trapped under of, and/or within, the paint film defects creating a new dielectric barrier to be permeated by the cathodic reagents before reaching the reaction surface. During this period, however, the $R_{2}$ values for the $A C$, EA and VL samples increased from the first EIS measurement. This rise was attributed to the fact that the low barrier effect offered by these painting systems rapidly enabled the attack of the underlying $55 \% \mathrm{Al}-\mathrm{Zn}$ and, consequently, the amount of developed corrosion products was enough to block both the paint defects and the substrate active areas. Thereafter, the cyclic mechanism consisting of appearance of protective failures at the weaker paint film substrate corrosion at these localized areas - blockage of them by the corrosion products made that $R_{2}$ values for all the samples ranged from $10^{5} \Omega \mathrm{cm}^{2}$ to $10^{9} \Omega \mathrm{cm}^{2}$. At the end of the test, the highest $\approx 10^{8} \Omega \mathrm{cm}^{2}$ and the lowest $\approx 10^{5} \Omega \mathrm{cm}^{2}$ charge transfer resistance values corresponded to the $\mathrm{VL}$ and $\mathrm{AQ}=\mathrm{EA}$ samples, respectively.

It is important to denote that, at least under this exposure condition, the $\mathrm{R}_{2}$ evolution did not follow linearly that of the $R_{1}$ one. This was interpreted by assuming that while no significant change of the free volume within the intact part of the painting system was detected (stable values of $\mathrm{C}_{1}$ ), the different adhesion loss shown by the anticorrosive primers caused the development of also dissimilar electrochemically active $55 \% \mathrm{Al}-\mathrm{Zn}$ areas and, consequently, an inversely proportional change of the corrosion resistance values [33].

The in general low values of the double layer capacitance $\left(C_{2} \approx 10^{-11}-10^{-8} \mathrm{Fcm}^{-2}\right)$ allowed to infer that the electrochemically active areas under the paint coat could be localized. So, assuming that the specific double layer capacitance of the bare metal is $C_{d l} \approx 20.10^{-6} \mathrm{Fcm}^{-2}$ [45], it was estimated that the active areas (defined as $A=C_{2} / C_{d l}$ ) ranged between $1.10^{-6}$ $1.10^{-3} \mathrm{~cm}^{2}$, that is to say, $0.00002-0.062 \%$ of the whole painted area [46]. 

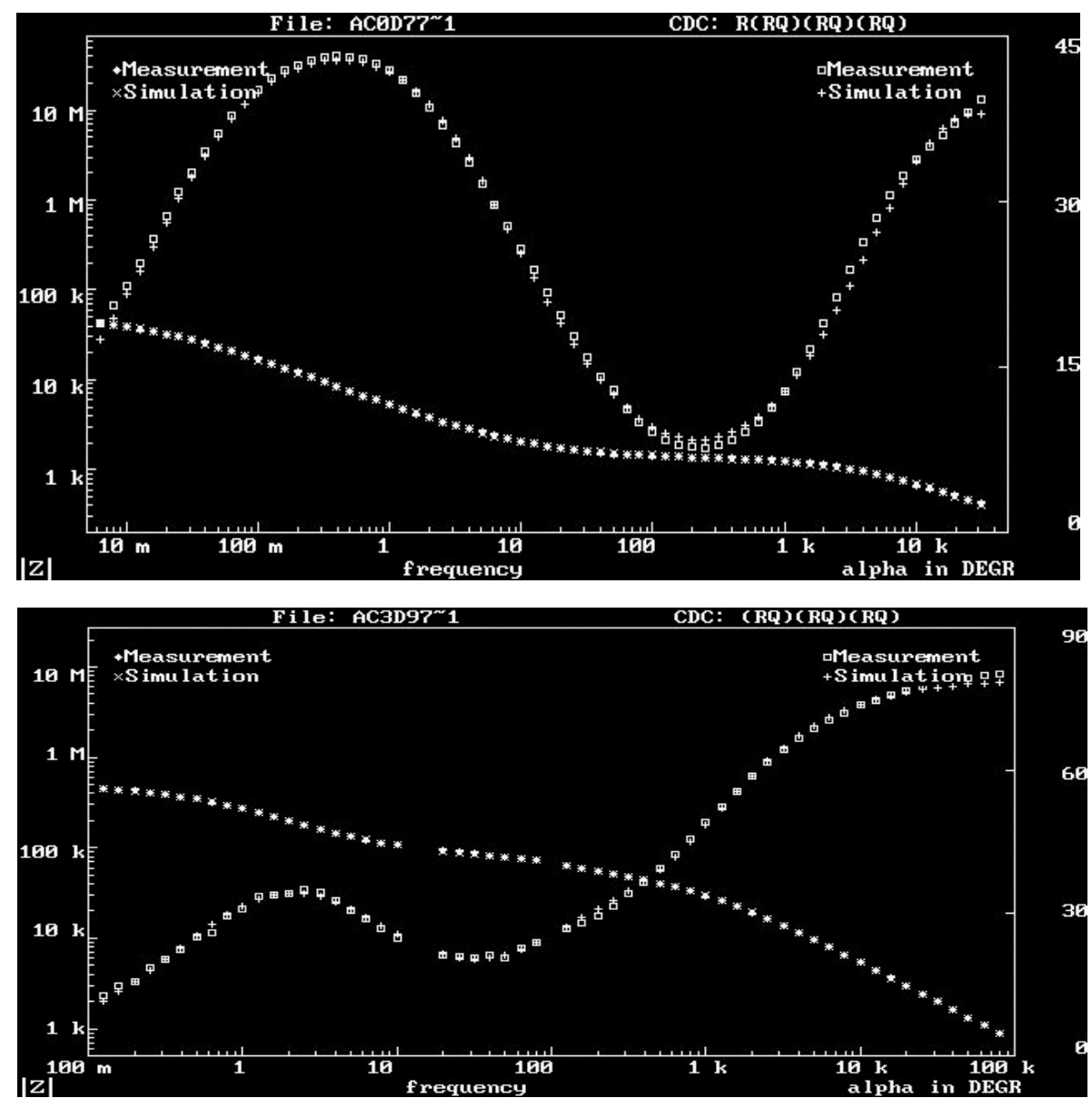

Fig. 7. Example of Bode plots displaying the measured and simulated (using the equivalente circuit shown in Fig. 6) impedance data

Figs. $8 \mathrm{e}$ and $\mathrm{f}$ point out that the third time constant $\left(\mathrm{R}_{3} \mathrm{C}_{3}\right)$ became visible 12 days after exposure. Its appearance was associated to the development of dielectric zinc corrosion products at the electrochemically active $55 \% \mathrm{Al}-\mathrm{Zn}$ areas, and their dynamic evolution over the exposure time to the corrosion products gathering within, and/or transport through, the painting system. It is clear that, as it was above mentioned, such a behavior is reflected by the evolution of the $R_{1}$ and $R_{2}$ values.

\subsubsection{Immersion exposure tests}

Figs. 9a, 10a and 11a show that the ionic resistance $\left(R_{1}\right)$ values determined for replicated samples submerged in $0.5 \mathrm{M} \mathrm{Na}_{2} \mathrm{SO}_{4}, 0.5 \mathrm{M} \mathrm{Na} \mathrm{Cl}$ or $0.25 \mathrm{M} \mathrm{NaCl}+0.25 \mathrm{M} \mathrm{Na}_{2} \mathrm{SO}_{4}$ solutions tended to fluctuate in the range $10^{4}-10^{9} \Omega \mathrm{cm}^{2}$ during the tests. The higher barrier effect was offered by the ES samples $\left(R_{1} \approx 10^{9}-10^{8} \Omega \mathrm{cm}^{2}\right)$, while the lower corresponded to the $A C$ and $A Q$ samples $\left(10^{5}-10^{3} \Omega \mathrm{cm}^{2}\right)$. Fortunately, these results are in line with those illustrated in Table 4, related to the barrier properties of each painting system. 
Regarding the dielectric capacitance $\left(C_{1}\right)$ evolution presented in Figs. 9b, 10b and $11 \mathrm{~b}$, it can be seen that once the water saturation level was reached, the more resistive painting systems exhibited a quasi steady state. The stability of the dielectric capacitance of the ES, $E A$, and $V L$ samples immersed in any electrolyte was approximately $10^{-10}-10^{-9} \mathrm{Fcm}^{-2}$, demonstrating that the intact part of the paint coating actually behaved like a dielectric capacitor during the immersion test. In addition, this means that the water uptake was less than $5 \%$ of the painting system volume [44].

A clear deterioration of the barrier property supplied by the AC system exposed to either 0.5 $\mathrm{M} \mathrm{Na}_{2} \mathrm{SO}_{4}, 0.5 \mathrm{M} \mathrm{NaCl}$ or $0.25 \mathrm{M} \mathrm{NaCl}+0.25 \mathrm{M} \mathrm{Na}_{2} \mathrm{SO}_{4}$ solutions, and in a lesser scale by the $A Q$ system, was given by the significant increase of its dielectric capacitance up to reaching $C_{1} \approx 10^{-6}-10^{-7} \mathrm{Fcm}^{-2}$ at the end of the test. Such increase was ascribed to both the declining of the barrier effect afforded by the painting system, and the adhesion loss (delamination) at the metal/paint interface, which enabled the electrolyte diffusion and accumulation.

The $R_{1}$ and $C_{1}$ parameters instability was interpreted assuming that the solution resistivity in the conducting pathways within the paint film and/or the size of the geometric area related with the free volume either within the same film or at the paint/metal interface changed during the immersion test in the three electrolytes according to the resin chemical composition. Consequently, the protection given by the painting system failed because the decline of its barrier resistance due to the electrolyte permeation cannot prevent the arrival of corrosion inducing species to the metallic surface. These chemicals, meaningfully anions such as $\mathrm{Cl}^{-}$and/or $\mathrm{SO}_{4}{ }^{2-}$, acting together with the water accumulated within and/or under the paint film provoked the appearance of a driving force able to overcome the activation energy of the anion diffusion process. In such circumstances, and after a certain induction period, whose length depends mainly on the paint film permeability and anion characteristics, the corrosion of the underlying $55 \% \mathrm{Al}-\mathrm{Zn}$ layer initiated. Not only are the size and electric charge of the $\mathrm{Cl}^{-}$ions less than those of the $\mathrm{SO}_{4}{ }^{2-}$ ones but also the solubility of their reaction products is greater. Therefore, it could be presumed that the diffusion rate of the $\mathrm{Cl}^{-}$ions through the organic coating layer would be less affected by eventual steric and/or electrochemical interactions with the coating reactive species. Evidence that the $\mathrm{Cl}^{-}$ions not only would arrive faster but also provoke more deterioration at the $55 \% \mathrm{Al}-\mathrm{Zn} /$ primer interface can be seen by comparing Figs. 9c-f, 10c-f and 11c-f, particularly when the AC and AQ samples are compared with the others. Likewise, taking into account that the parameters $\left(R_{2}\right.$ and $\mathrm{C}_{2}$ ) associated to the faradaic process could be deconvoluted from the impedance spectra obtained the first day of exposure Figs. 9c-d, 10c-d and 11c-d, it is clear that the painted steel/55\%AI-Zn underwent a quick but localized corrosion attack. The intensity and rate of this attack were dependent on the protective properties of the applied painting system. Nevertheless, still in the $A C$ and $A Q$ samples where the anticorrosive protection was less effective, the appearance of the time constant $\left(\mathrm{R}_{3} \mathrm{C}_{3}\right)$ associated to the contribution of the corrosion products to the overall sample impedance took place after a certain induction period. Therefore, it was inferred that despite their poor performance, the painting systems were able to delay, and in some case to reduce, the corrosion rate in such a way that the mentioned corrosion products could not be detected by naked eye after 115 days of exposure (see Table 4). In all the cases, the rds was under activated control, i.e., by the underlying metal dissolution. 

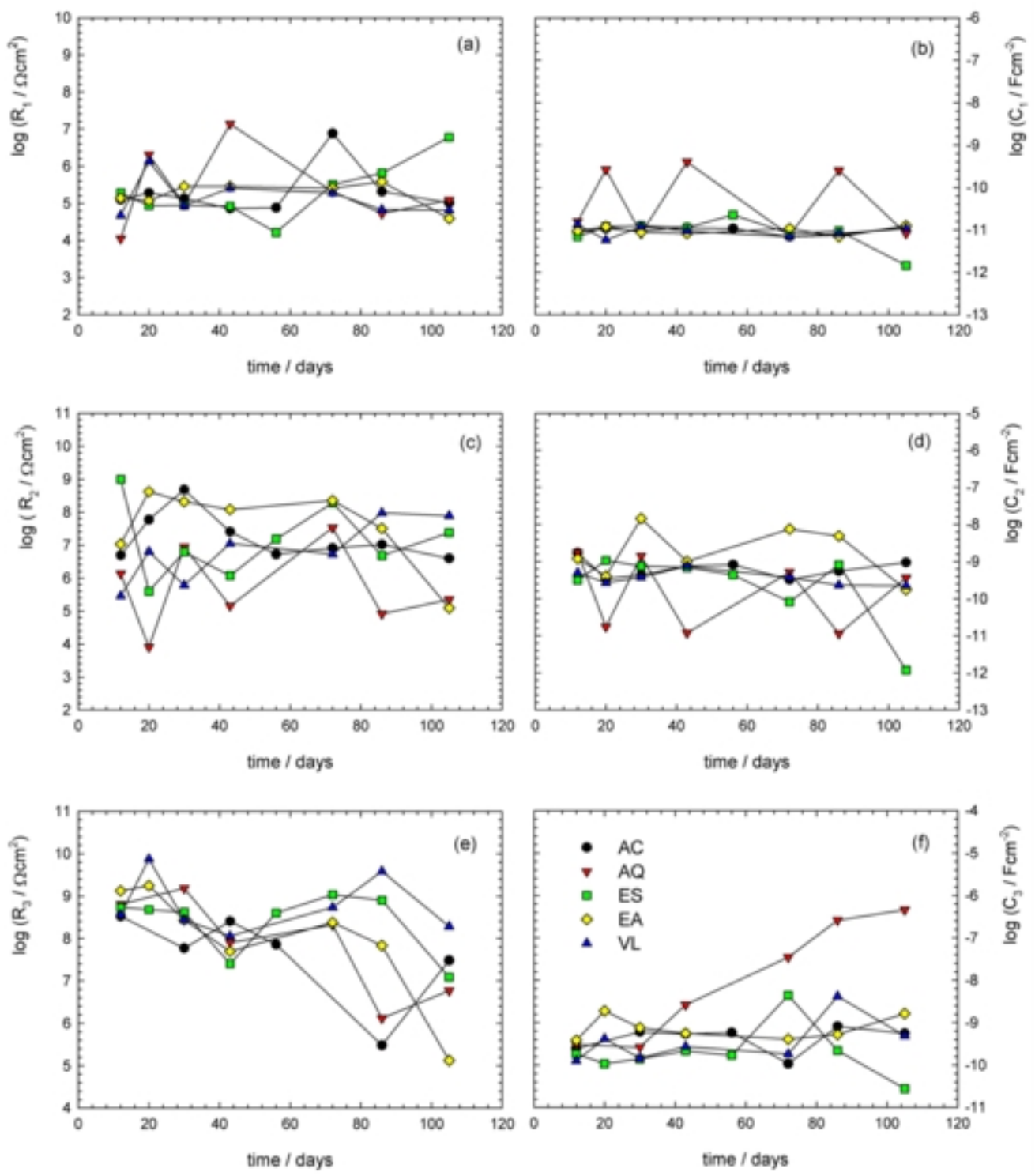

Fig. 8. Evolution of a) $\log R_{1}$; b) $\log C_{1}$; c) $\log R_{2}$; d) $\log C_{2}$; e) $\log R_{3}$; and f) $\log C_{3}$ parameters of $A C, A Q, E S, E A$ and $V L$ samples exposed in salt spray chamber for 105 days 

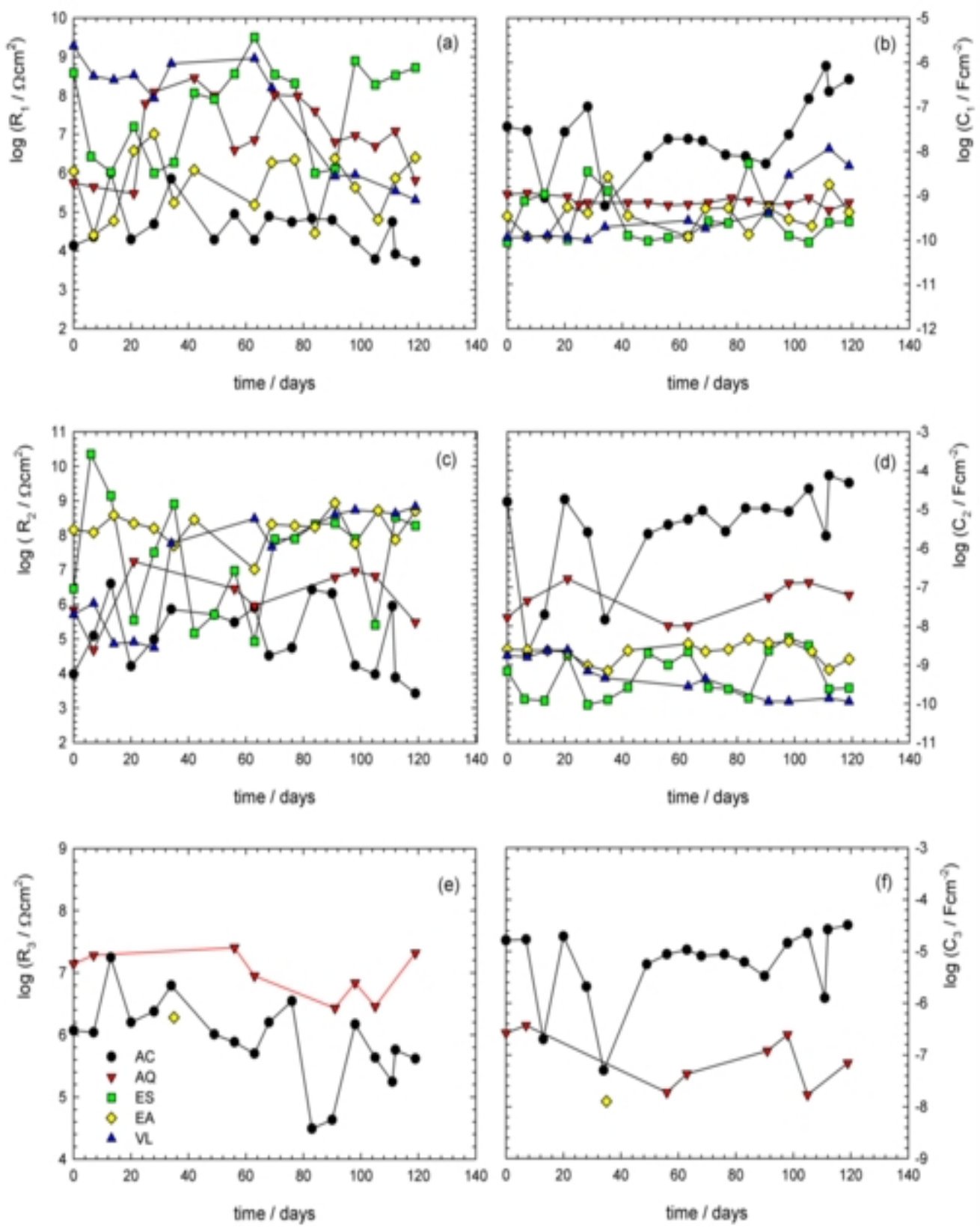

Fig. 9. Evolution of a) $\log R_{1}$; b) $\log C_{1}$; c) $\log R_{2}$; d) $\log C_{2}$; e) $\log R_{3}$; and f) $\log C_{3}$ parameters of $A C, A Q, E S, E A$ and $V L$ samples immersed for 120 days in $0.5 \mathrm{M} \mathrm{Na}_{2} \mathrm{SO}_{4}$ solution 

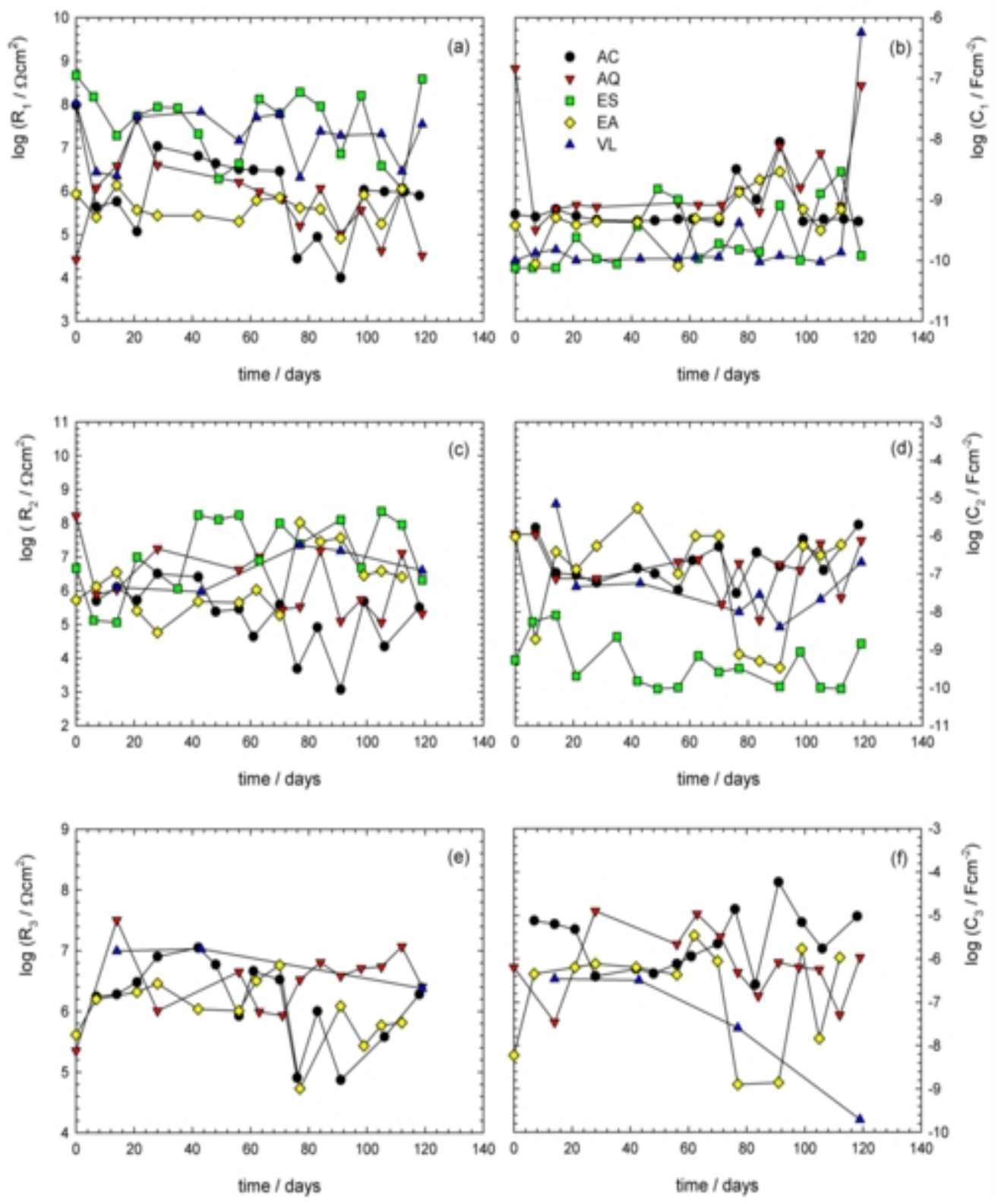

Fig. 10. Evolution of a) $\log R_{1}$; b) $\log C_{1}$; c) $\log R_{2}$; d) $\log C_{2}$; e) $\log R_{3}$; and f) $\log C_{3}$ parameters of $A C, A Q, E S, E A$ and $V L$ samples immersed for 120 days in $0.5 \mathrm{M} \mathrm{NaCl}$ solution 

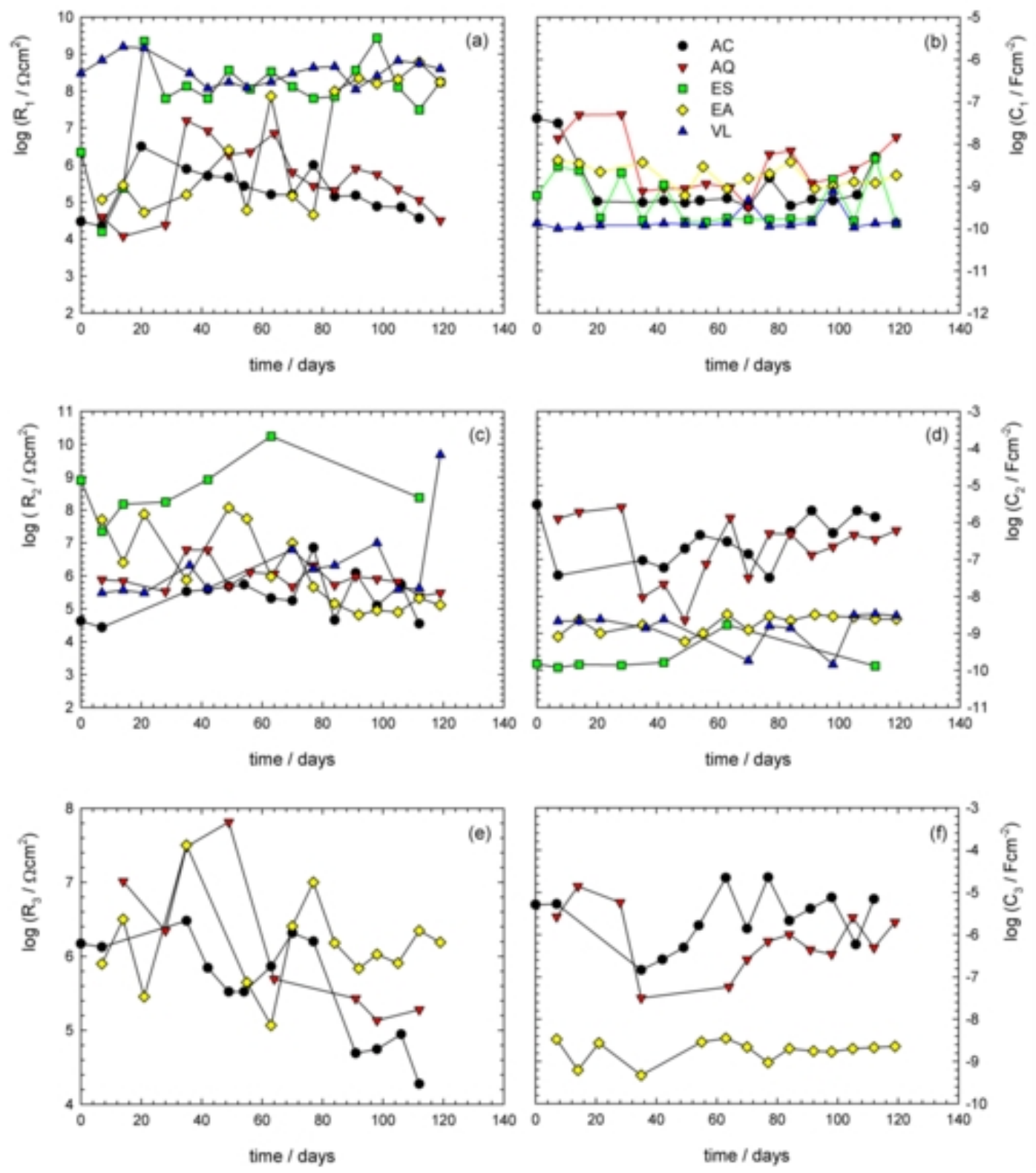

Fig. 11. Evolution of a) $\log R_{1} ;$ b) $\log C_{1}$; c) $\log R_{2} ;$ d) $\log C_{2}$; e) $\log R_{3}$; and f) $\log C_{3}$ parameters of $A C, A Q, E S, E A$ and $V L$ samples immersed for 120 days in $0.25 \mathrm{M} \mathrm{Na}_{2} \mathrm{SO}_{4}+0.25 \mathrm{M} \mathrm{NaCl}$ solution

\section{CONCLUSION}

The experimental behavior of the treated panels was evaluated through visual inspection (blistering and/or white corrosion degrees) and EIS measurements (corrosion evolution). EIS spectra were interpreted and discussed in terms of the time dependence of the electrical 
(paint coating) and electrochemical (steel/55\%AI-Zn substrate) parameters associated with interfacial processes to describe the deterioration of the metal/paint system.

Of the five painting systems studied under different exposure conditions, the one identified as ES presented the best overall anticorrosive behavior when immersed in $0.5 \mathrm{M} \mathrm{Na}_{2} \mathrm{SO}_{4}$, $0.5 \mathrm{M} \mathrm{NaCl}$ or $0.25 \mathrm{M} \mathrm{NaCl}+0.25 \mathrm{M} \mathrm{Na}_{2} \mathrm{SO}_{4}$ solution because it has lowest water diffusion and permeability coefficients. The results offered by the rest of the painting systems were electrolyte dependent and fluctuated from intermediate (EA and VL samples) to very poor ( $A C$ and $A Q$ samples). With regard to the salt spray exposure test, it may be concluded that most of the painting systems performed satisfactorily.

The correlation of results from the standardized and electrochemical tests allowed for the explanation of some problems observed in practice and opened the door to extend the useful life by improving the paint formulation and/or the painting system design.

All the laboratory tests involved in this work were useful to understand the behavior of the studied painting systems subjected to highly aggressive environments. The good correlation between standardized (blistering, white corrosion, salt spray chamber) and electrochemical (impedance spectra, corrosion potential) tests allowed explaining some problems observed in practice and, on this base, they could help to solve at least part of them either changing some components or concentrations of the paint formulation to maintain its useful life as long as possible. Besides, the rather scattered results observed by comparing the anticorrosive protective properties afforded by a given painting system exposed to different media support the idea that extrapolating protective performances from an exposure condition to other is absolutely risky.

\section{ACKNOWLEDGEMENTS}

The authors thank to the Comisión de Investigaciones Científicas de la Provincia de Buenos Aires (CICPBA), the Consejo Nacional de Investigaciones Científicas y Técnicas (CONICET) and the Universidad Nacional de La Plata of Argentina by the financial support to carry out the present research paper. They also thank to the Engr. A. Aznar by the formulation of the acrylic and epoxy waterborne paints.

\section{COMPETING INTERESTS}

Authors have declared that no competing interests exist.

\section{REFERENCES}

1. Nazarov A, Prosek T, Thierry D. Application of EIS and SKP methods for the study of the zinc/polymer interface. Electrochim. Acta. 53;2008:7531-7538.

2. Edavan RP, Kopinski R. Corrosion resistance of painted zinc alloy coated steels. Corros. Sci. 2009;51:2429-2442.

3. Pourbaix M. Une méthode éléctrochimique rapide de predetermination de la corrosion atmospherique. Rapports Techniques CEBELCOR. 1969;109:1.

4. $\quad$ ASM Handbook, ASM International (Ed.), Corrosion.1992;13:399. 
5. Seré PR, Zapponi M, Elsner Cl, Di Sarli AR. Comparative corrosion behaviour of 55Aluminium-Zinc alloy and zinc hot dip coatings deposited on low carbon steel substrates. Corros. Sci. 1998:39(10):1711-1723.

6. Van Eijnsbergen JFH. Duplex Systems-Hot Dip Galvanising Plus Painting, New York, NY, Elsevier Science B.V. vol. 1994;7:75.

7. Ogle K, Morel S, Meddahi N. An electrochemical study of the delamination of polymer coatings on galvanized steel. Corros. Sci. 2005;47:2034-2052.

8. Vu AQ, Vuillemin B, Oltra R, Allély C. Cut-edge corrosion of a Zn-55Al-coated steel: A comparison between sulphate and chloride solutions. Corros. Sci. 2011;53:30163025.

9. K. Ogle, S. Morel, N. Meddahi. An electrochemical study of the delamination of polymer coatings on galvanized steel. Corrosion Science. 2005;47:2034-2052.

10. Yang H, Kong X, Lu W, Liu Y, Guo J, Liu S. High anticorrosion chromate-free passive films made by Titanate and waterborne polyurethane on galvanized steel sheet. Prog. Org. Coat. 2010;67:375-380.

11. El-Mahady GA, Nishikata, Tsuru AT. AC impedance study on corrosion of $55 \% \mathrm{Al}-\mathrm{Zn}$ alloy-coated steel under thin electrolyte layers. Corros. Sci. 2000;42(9):1509-1521.

12. Matsuzaki A, Yamaji T, Yamashita M. Development of a new organic composite coating for enhancing corrosion resistance of $55 \% \mathrm{Al}-\mathrm{Zn}$ alloy coated steel sheet. Surf. Coat. Technol. 2003;169;655-657.

13. Huttunen-Saarivirtaa E, Yudinb VE, Myagkovab LA, Svetlichnyib VM. Corrosion protection of galvanized steel by polyimide coatings: EIS and SEM investigations. Prog. Org. Coat. 2011;72:269-278.

14. Mertens SF, Xhoffer C, De Cooman BC, Temmerman E. Short-term deterioration of polymer-coated $55 \% \mathrm{Al}-\mathrm{Zn}$ : Part 1 - Behavior of thin polymer films. Corrosion, 1997;53(5):381-388.

15. Chiba A, Muto I, Hara N. Cut edge corrosion inhibition by chromate in primer of prepainted 55\% Al-Zn coated steel. J. Electrochem. Soc. 2011;158(3):42-47.

16. Hörnström SE, Karlsson J, Van Ooij W, Nie T, Klang H. Paint adhesion and corrosion performance of chromium-free pretreatments of $55 \% \mathrm{Al}-\mathrm{Zn}$-coated steel. J. Adh. Sci. Technol. 1996;10(9):883-904.

17. Gerhard A, Bittner A. Second Generation Phosphate Anti-Corrosive Pigments. Formulating Rules for lull Replacement of New Anti-Corrosive Pigments. J. Coat. Technol. 1986;58(740):59-65.

18. Bittner A. Advanced Phosphate Anticorrosive Pigments For Compliant Primers. J. Coat. Technol. 1989;61(777):14-1IS.

19. Adrian G, Gerhard A, Bittner A, Gawol M. New phosphate anti-corrosive pigments. Farbe u. Lack, 1981;87(10):833-836.

20. Boukamp BA. Report CT88/265/128, CT89/214/128, University of Twente, The Netherlands; 1989.

21. Schwiderke EE, Di Sarli AR. A mathematical basis for calculating the water permeability of organic films supported by metal substrates. Prog. Org. Coat. 1987; 14:297-308. 
22. Ritter JJ, Kruger J. Corrosion Control by Organic Coating, H. Leidheiser, Jr. ed., NACE, Houston, TX. 1981;28.

23. Wolstenholme J. Electrochemical methods of assessing the corrosion painted metalsa review. Corros. Sci. 1973;13(7):521-530.

24. Armas RA, Gervasi C, Di Sarli AR, Real SG, Vilche JR. Zinc rich paints on steels in artificial sea water by electrochemical impedance spectroscopy. Corrosion, 1992;48:379-383.

25. Mayne JEO. The mechanism of the inhibition of the corrosion of iron and steel by means of paint. Official Digest, 1952;24:127-136.

26. Meszáros L, Lindquist AS. Proc. Conference EUROCORR'82-115 ${ }^{\text {th }}$ Event of the European Federation for Corrosion, Budapest, Hungary-18-22 October. 1982;11:147.

27. Morcillo M, Barajas R, Feliú S, Bastidas JM. A-SEM Study on the Galvanic Protection of Zinc-Rich Paints. J. Mat. Sci. 1990;25:2441-2446.

28. Kendig MW, Leidheiser H Jr. The Electrical Properties of Protective Polymer Coatings as Related to Corrosion of the Substrate. J. Electrochem. Soc. 1976;123:982-989.

29. Guenbour A, Faunchen J, Ben Bachir A. On the Mechanism for Improved Passivation by Addition of Molybdenum to Austenitic Stainless Steels in O-Phosphoric Acid. Corrosion, 1988;44(4):214-221.

30. Ambrose JR. Role of molybdenum as an inhibitor of localized corrosion on iron in chloride solutions. Corrosion, 1978;34(1):27-31.

31. Byrnes G. Generic Coating Types. An Introduction to Industrial Maintenance Coating Materials. Technology Publishing Company, LI. M. Smith (ed.), Pittsburgh, PA, USA. 1996;19.

32. Hare CH. Water Permeability in pigmented paints. J. Protect. Coat. \& Lining. 1997;7794.

33. del Amo B, Véleva L, Elsner Cl, Di Sarli AR. Performance of coated steel systems exposed to different media. Part I: Painted galvanised steel. Prog. Org. Coat. 2004;50(3):179-192.

34. Ferraz O, Cavalcanti E, Di Sarli AR. The characterization of protective properties for some naval steel/polymeric coating/3\% $\mathrm{NaCl}$ solution systems by EIS and visual assessment. Corros. Sci. 1995;37(8):1267-1280.

35. Seré PR, Santágata DM, Elsner CI, Di Sarli AR. The influence of the method of application of the paint on the corrosion of the substrate as assessed by ASTM and electrochemical method. Surf. Coat. Intern. 1998;3:128-134.

36. Santágata DM, Seré PR, Elsner Cl, Di Sarli AR. Evaluation of the surface treatment effect on the corrosion performance of paint coated carbon steel. Prog. Org. Coat. 1998;33:44-54.

37. Seré PR, Armas AR, Elsner Cl, Di Sarli AR. Comparative Corrosion Behaviour Of 55\%Al-Zn Alloy And Zinc Hot Dip Coatings Applied On Low Carbon Steel Substrates. Corros. Sci. 1998;40(10):1711-1723.

38. Elsner $\mathrm{Cl}$, Cavalcanti E, Ferraz O, Di Sarli AR. Evaluation of the surface treatment effect on the anticorrosive performance of paint systems on steel. Prog. Org. Coat. 2003;48(1):50-62 . 
39. Leidheiser H Jr., Kendig MW. The Mechanism of Corrosion of Polybutadiene Coated Steel in Aerated Sodium Chloride. Corrosion, 1976;32:69-75.

40. Nascimento GG, Mattos OR, Santos JL, Margarit ICP. Impedance measurements on lacquered tinplate: fitting with equivalent circuits. J. Appl. Electrochem. 1999;29:383392.

41. Szauer T, Brandt A. Impedance measurements on zinc-rich paints. J. Oil Col. Chem. Assoc. 1984;67:13-17.

42. Frydrych DJ, Farrington GC, Townsend HC. Corrosion Protection by Organic Coatings (M.W. Kendig \& H. Leidheiser, Jr. Ed.), vol. 87-2, The Electrochem. Soc., Pennington, NJ. 1987;240.

43. van Westing EPM, Ferrari GM, Geenen FM, van de Wit JHW. In situ determination of the loss of adhesion of barrier epoxy coatings using electrochemical impedance spectroscopy. Prog. Org. Coat. 1993;23:89-103.

44. Brasher DM, Kingsbury AA. Electrical measurements in the study of immersed paint coatings on metal. I. Comparison between capacitance and gravimetric methods of estimating water-uptake. J. Appl. Chem.1954;4(2):62-72.

45. Dattilo $M$. Use of $A C$ impedance to determine the corrosion rate of electrogalvanized steel. Mat. Performance. 1986;25(11):18-22.

46. Elsner $\mathrm{Cl}$, Cavalcanti E, Ferraz O, Di Sarli AR. Evaluation of the surface treatment effect on the anticorrosive performance of paint systems on steel, Prog. Org. Coat. 2003;48(1);50-62.

(C) 2014 Sarli and Elsner; This is an Open Access article distributed under the terms of the Creative Commons Attribution License (http://creativecommons.org/licenses/by/3.0), which permits unrestricted use, distribution, and reproduction in any medium, provided the original work is properly cited.

Peer-review history:

The peer review history for this paper can be accessed here: http://www. sciencedomain.org/review-history. php?iid=429\&id=31\&aid=3786 